\title{
Multi-criteria placement and capacity selection of solar power plants in the "Baikal-Khövsgöl" Cross-Border Recreation Area
}

\author{
Irina Ivanova ${ }^{1}$, Vladislav Shakirov ${ }^{1, *}$ \\ ${ }^{1}$ Melentiev Energy Systems Institute of Siberian Branch of the Russian Academy of Sciences, Department of Complex and Regional \\ Problems in Energy, Irkutsk, Russia
}

\begin{abstract}
The problem of power supply to remote consumers in the "Baikal-Khövsgöl" Cross-Border Recreation Area, associated with the high length and low reliability of power lines is discussed. The assessment of the modes of the power distribution grid showed that the introduction of new consumers in this territory will lead to unacceptable voltage deviations, even taking into account the installation of reactive power compensating devices. Since the area under consideration has a high solar energy potential, it is advisable to use distributed solar generation. The choice of locations and capacities of solar power plants is a multi-criteria optimization problem. Four criteria are proposed: total voltage deviation, total active power losses, reliability and capital costs for construction. An algorithm for multi-criteria optimizationis developed and implemented as a program in the MATLAB, which consists in sequential verification of the feasibility of installing additional power of solar power plants at the consumers of each of the substations under consideration. For each variant, the electric grid mode is assessed using the Power system analysis toolbox program. Solutions for the choice of locations and capacities of solar power plants are obtained, providing high scores by criteria in accordance with the given criteria importance coefficients.
\end{abstract}

\section{Introduction}

"Baikal-Khövsgöl" cross-border recreation area runs from the southern part of Lake Baikal through Tunkinsky and Okinsky regions of the Republic of Buryatia (Russia) to Lake Hubsugul through somon Khanh (Mongolia). This area is very promising for international tourism development. There are two major national parks - Khövsgöl (Mongolia) and Tunkinsky (Russia), many health resorts, recreation centers, places of tourist and recreational type. In close proximity, on the Russian-Mongolian border, is the highest peak of the Sayan - Mount Munku-Sardyk, which is a popular site for sports tourism [1].

At present, specially protected natural areas (SPNAs) are actively involved in ecotourism: new economic mechanisms for their functioning are being introduced; they are being integrated into the sphere of social and economic development; budget financing is being increased; and participation in conservation projects is being expanded $[1,2]$.

For the sustainable socio-economic development of "Baikal-Khövsgöl" cross-border recreation area, it is necessary to ensure environmentally efficient and reliable power supply to existing and prospective consumers in accordance with the requirements to power quality GOST R 32144-2013 and European standard EN 50160-2010 [3].

At present, the power supply system has low reliability. On the Russian side, the key elements of the power supply system are the $110 / 35 / 10 \mathrm{kV}$ "Kyren" and $110 / 35 / 10$ "Zun-Murino" substations located in Tunkinsky Raion (Fig. 1). Consumers in Okinsky Raion are supplied with electric power via a single-circuit 110 $\mathrm{kV}$ power line "Kyren - Mondy - Samarta", a singlecircuit $35 \mathrm{kV}$ power line "Mondy - Sorok - Samarta" and a single-circuit $35 \mathrm{kV}$ power line "Sorok - Orlik". Long radial single-circuit power lines are characterized by significant wear and frequent prolonged shutdowns [4]. For example, if one of the power lines is damaged, about 4360 people, 1 hospital, 6 schools, 6 kindergartens, 7 boiler houses and 5 settlements are disconnected. There are no redundant power lines available. The restoration work is complicated by the mountainous terrain and the long length of power lines. These districts are among the underdeveloped and hardto-reach places in the Republic of Buryatia.

In Mongolia, the considered cross-border area within the borders of the Khanh somon is not provided with its own generation, there is no connection with the state energy system. Power supply to the Khankh settlement is carried out from the Republic of Buryatia through the interstate $10 \mathrm{kV}$ transmission line "Mondy-Zavod" with a length of $35 \mathrm{~km}$ (Fig. 1).

An additional problem is the low voltage level of consumers, due to the long length of power lines. The introduction of new consumers raises the question of using additional voltage regulation devices.

Thus, according to the Strategy of socio-economic development of the Republic of Buryatia for the period

* Corresponding author: shakirov@isem.irk.ru 


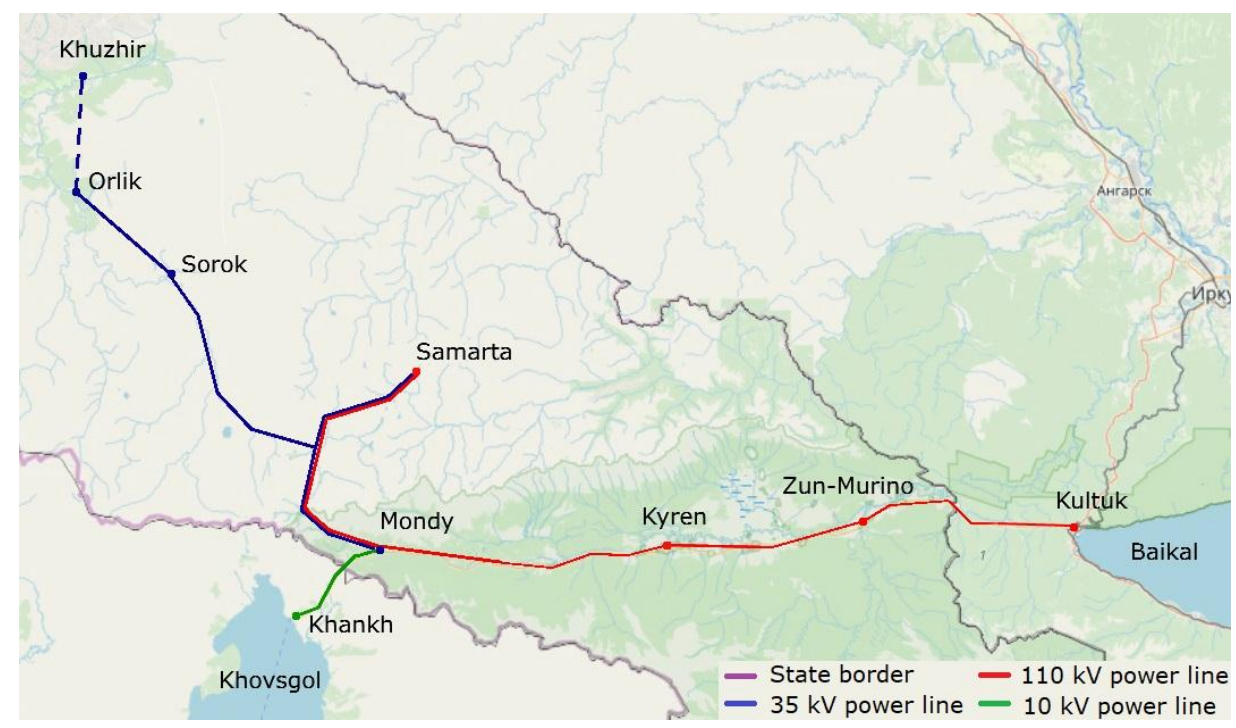

Fig. 1. General layout plan of the "Baikal-Khövsgöl" cross-border recreation area.

up to 2035 , in the period up to 2021 it is planned to develop and start operation of Konevinsky gold deposit [4]. For its power supply the construction of Khuzhir substation is planned (Fig. 1). The assessment of electric modes performed in [4] showed that the use of reactive power compensating devices will not allow to solve the problem of voltage level at consumers.

The territory under consideration has a high level of solar energy potential [4]. The average annual total solar radiation entering the horizontal surface is $1200-1350$ $\mathrm{kWh} / \mathrm{m}^{2}$. The expected capacity utilization factor of photovoltaic converters is at a relatively high level, in the range of $18.3-19.7 \%$. Installation of solar power plants (SPP) in settlements will improve the reliability of power supply, provide the required voltage level for consumers, and reduce the active power losses [5-8].

The problem of choosing the locations and capacity of renewable energy sources (RES) to improve the efficiency of power distribution grids has been considered in many works [9-13]. Heuristic optimization methods are widely used to solve this problem. In papers [14-17] the approaches on the basis of the intersect mutation differential evolution algorithm, back-tracking search algorithm, genetic algorithm, bionic algorithms are offered. The placement and selection of the capacity of renewable energy sources is carried out mainly from the standpoint of minimizing active power losses and voltage deviation among consumers.

In addition to the abovementioned criteria, the factors of power supply reliability and economic efficiency play a major role. As a rule, it is impossible to achieve high marks on all criteria at the same time. To find effective options for installed capacity and locations of RES, it is necessary to use a multi-criteria approach, which allows to determine compromise solutions, according to the relative importance of the criteria.

A multi-criteria heuristic approach to placement and selection of SPP installed capacity in the power distribution grid is proposed using 4 criteria: total voltage deviation at consumers, active power losses, reliability of power supply and capital costs for construction of SPP.

\section{Power flow analysis using the Power System Analysis Toolbox}

Fig. 2 shows the principal scheme of power supply to the territory under consideration, dashed line shows the planned construction of power transmission line and $35 / 10$ Khuzhir substation for power supply of Konevinsky gold deposit.

To assess the mode of the power distribution grid, the Power System Analysis Toolbox (PSAT) was used, which is controlled in the MATLAB environment [18].

PSAT raw data can be imported from electrical system models created in MATLAB Simulink. In Figure 3 shows a $35 \mathrm{kV}$ power distribution grid model created in MATLAB Simulink with the supply substation Samarta 110/35/6 kV. The model includes an interstate $10 \mathrm{kV}$ transmission line Mondy-Khankh.

Tables 1, 2 show the accepted values of the electrical loads and the results the bus voltage estimation for several modes of the power grid:

Mode 1 - without taking into account the commissioning of the Khuzhir substation;

Mode 2 - taking into account the commissioning of the Khuzhir substation;

Mode 3 - taking into account the commissioning of the Khuzhir substation and full compensation of reactive power at consumers.

As a result of commissioning of Khuzhir substations, the voltage at the consumers of Monda, Khanh, Sorok, Orlik substations have inadmissible deviations from the nominal values according to GOST R 32144-2013, EN $50160-2010$, more than $10 \%$. It is also possible to note rather high active power losses.

With full compensation of reactive power at the considered substations, inadmissible high voltage deviations are preserved at the substations Sorok, Orlik and Khuzhir, the active power losses are reduced, but remain at a high level. 


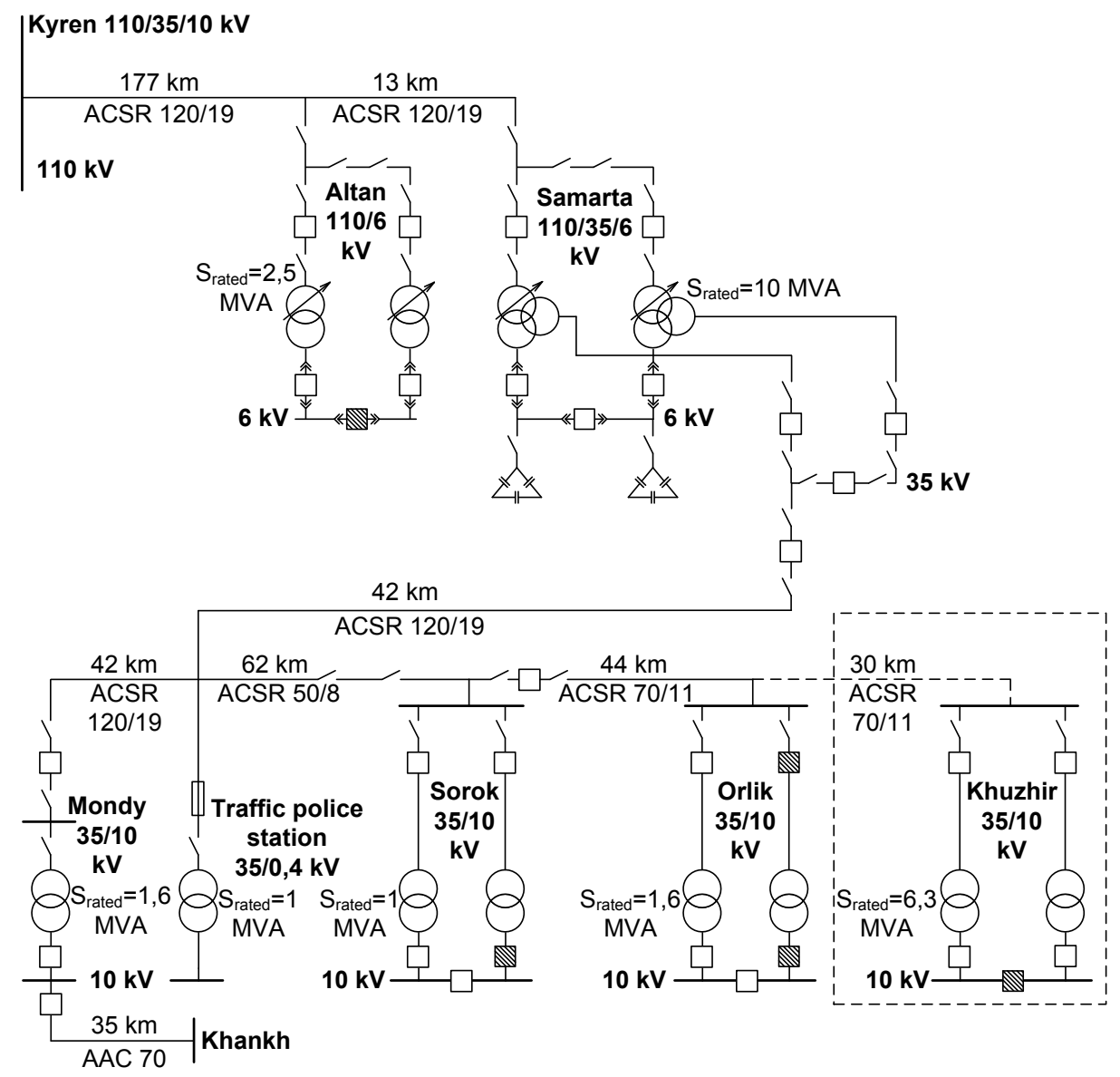

Fig. 2. Schematic diagram of the power distribution grid.

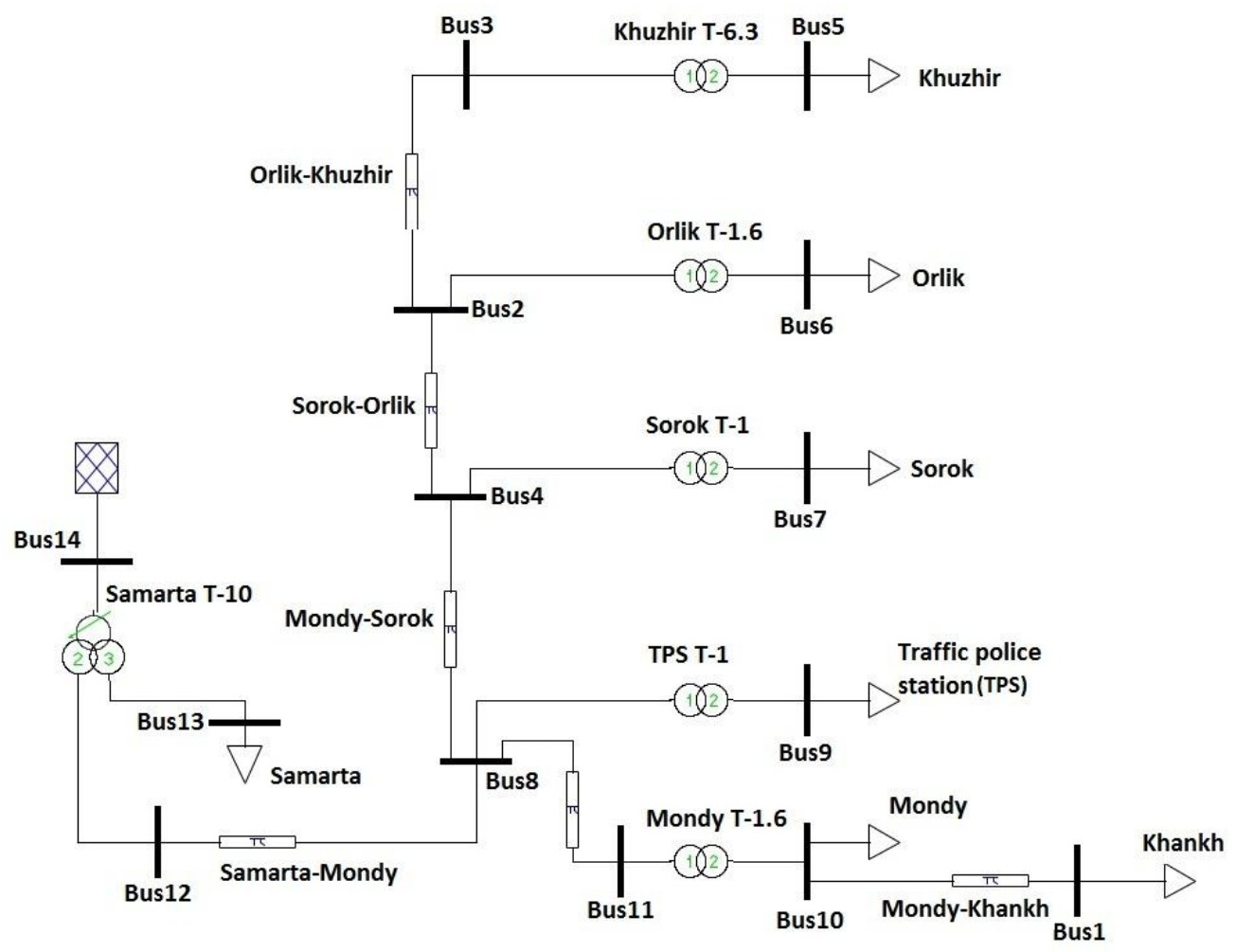

Fig. 3. Power distribution grid model for the PSAT. 
Table 1. Accepted values of electrical loads.

\begin{tabular}{|c|c|c|c|c|c|c|}
\hline \multirow[t]{2}{*}{ Locality } & \multicolumn{3}{|c|}{$\mathrm{P}, \mathrm{MW}$} & \multicolumn{3}{|c|}{ Q, MVar } \\
\hline & Mode 1 & Mode 2 & Mode 3 & Mode 1 & Mode 2 & Mode 3 \\
\hline Samarta & \multicolumn{3}{|c|}{11.6} & \multicolumn{2}{|c|}{5.3} & 0 \\
\hline Mondy & \multicolumn{3}{|c|}{1.3} & \multicolumn{2}{|c|}{0.6} & 0 \\
\hline Khankh & \multicolumn{3}{|c|}{0.35} & \multicolumn{2}{|c|}{0.1} & 0 \\
\hline TPS & \multicolumn{3}{|c|}{0.1} & \multicolumn{2}{|c|}{0.1} & 0 \\
\hline Sorok & \multicolumn{3}{|c|}{0.7} & \multicolumn{2}{|c|}{0.2} & 0 \\
\hline Orlik & \multicolumn{3}{|c|}{0.7} & \multicolumn{2}{|c|}{0.2} & 0 \\
\hline Khuzhir & 0 & 1.8 & 1.8 & 0 & 0.5 & 0 \\
\hline
\end{tabular}

Table 2. Results of assessing the voltage on the load buses and active power losses in the power grid.

\begin{tabular}{|c|c|c|c|c|c|c|c|c|c|c|c|c|c|c|c|}
\hline Locality & \multicolumn{2}{|c|}{ Samarta } & \multicolumn{2}{|c|}{ Mondy } & \multicolumn{2}{|c|}{ Khankh } & \multicolumn{2}{|c|}{ TPS } & \multicolumn{2}{|c|}{ Sorok } & \multicolumn{2}{|c|}{ Orlik } & \multicolumn{2}{|c|}{ Khuzhir } & \multirow{2}{*}{$\begin{array}{c}\Delta P_{\Sigma}, \\
\%\end{array}$} \\
\hline Mode $\quad$ Parameters & $\begin{array}{l}U, \\
\mathrm{kV}\end{array}$ & $\begin{array}{c}\delta U, \\
\%\end{array}$ & $\begin{array}{c}U, \\
\mathrm{kV}\end{array}$ & $\begin{array}{c}\delta U, \\
\%\end{array}$ & $\begin{array}{l}U, \\
\mathrm{kV}\end{array}$ & $\begin{array}{c}\delta U, \\
\%\end{array}$ & $\begin{array}{l}U, \\
\mathrm{\kappa B}\end{array}$ & $\begin{array}{c}\delta U, \\
\%\end{array}$ & $\begin{array}{c}U, \\
\mathrm{kV}\end{array}$ & $\begin{array}{c}\delta U, \\
\%\end{array}$ & $\begin{array}{c}U, \\
\mathrm{kV}\end{array}$ & $\begin{array}{c}\delta U, \\
\%\end{array}$ & $\begin{array}{c}U, \\
\mathrm{kV}\end{array}$ & $\begin{array}{c}\delta U, \\
\%\end{array}$ & \\
\hline Mode 1 & 6.47 & 2.74 & 9.79 & -6.75 & 9.2 & -12.39 & 10.55 & 0.45 & 9.8 & -6.68 & 9.77 & -6.99 & - & - & 2.2 \\
\hline Mode 2 & 6.38 & 1.22 & 8.93 & -14.94 & 8.27 & -21.23 & 9.77 & -6.92 & 7.54 & -28.20 & 6.79 & -35.32 & 6.44 & -38.70 & 10.87 \\
\hline Mode 3 & 6.77 & 7.42 & 10.43 & -0.62 & 10.0 & -4.79 & 10.74 & 2.29 & 9.43 & -10.16 & 8.99 & -14.42 & 8.77 & -16.43 & 6.02 \\
\hline
\end{tabular}

Distributed generation units, including those based on RES, can be used to increase reliability of power supply, reduce voltage deviations and decrease active power losses in the grid.

\section{Multi-criteria placement and capacity selection of solar power plants}

The choice of locations and capacities of RES in the power distribution grid is a multi-criteria optimization problem. In the paper, the optimization process was aimed at improving four indicators:

1. Minimization of the total voltage deviation at load buses:

$$
\delta U_{\Sigma}=\sum_{i=1}^{n}\left|\delta U_{i}\right|
$$

where $\delta U_{i}$ is the voltage deviation from the nominal value at load bus $i, \%$.

2. Minimization of total active power losses:

$$
\Delta P_{\Sigma}=\sum_{j=1}^{k}\left|\Delta P_{j}\right|,
$$

where $\Delta P_{j}-$ the loss of active power in $j$-th element of the power grid, $\mathrm{kW}$.

3. Maximizing the indicator of the reliability of power supply to consumers, which was estimated by the share of load coverage of the important consumers by renewable energy sources at each substation:

$$
R=\sum_{i=1}^{n} \frac{1}{n \cdot L_{i}}\left[\min \left(L_{i} ; \frac{P_{r e i}}{P_{i}}\right)\right],
$$

where $n$ is the number of substations; $L_{i}$ is the share of the load of the $i$-th substation attributable to the important consumers, p.u.; $P_{\text {rei }}$ is the capacity of RES installed at the consumers of the i-th substation, $\mathrm{kW} ; P_{i}$ is the load of the $i$-th substation, $\mathrm{kW}$.
4. Minimization of capital costs for RES:

$$
C=\sum_{i=1}^{n} w_{t} \cdot P_{r e i}
$$

where $w_{t}$ is a specific capital investments in construction of the type $t$ renewable energy sources with installed capacity of $1 \mathrm{~kW}$, thousand rubles/kW.

The objective function is defined by the expression:

$$
\begin{aligned}
& V(x)=k_{1} \frac{\delta U_{1 \Sigma}-\delta U_{x \Sigma}}{\delta U_{1 \Sigma}}+k_{2} \frac{\Delta P_{1 \Sigma}-\Delta P_{x \Sigma}}{\Delta P_{1 \Sigma}}+ \\
& +k_{3} R_{x}+k_{4} \frac{C_{\text {max }}-C_{x}}{C_{\text {max }}},
\end{aligned}
$$

where $k_{1}, k_{2}, k_{3}, k_{4}$ are criteria importance coefficients, p.u.; $\delta U_{1 \Sigma}, \Delta P_{1 \Sigma}$ - total voltage deviation and active power losses corresponding to the power grid without RES; $\delta U_{x \Sigma}, \Delta P_{x \Sigma}$ - total voltage deviation, active power losses, corresponding to power grid with the $x$ option of locations and capacity of RES; $R_{x}$ is the assessment of the reliability of power supply to consumers with the $x$ option of locations and capacity of RES; $C_{x}$ - capital costs for the construction of RES with the $x$ option of locations and capacity of RES, million rubles; $C_{\max }-$ capital costs with full coverage of consumers' load using renewable energy sources, million rubles.

A larger value of the objective function corresponds to a more preferable option of locations and capacity of RES in the distribution power grid.

The determination of the importance coefficients values can be carried out by direct assignment by a decision-maker (DM), or determined using well-known procedures implemented within the AHP [19], MAUT [20] methods. Coefficients $k$ can take values from 0 to 1 .

Optimization of the locations and installed capacity of SPP is carried out in accordance with the algorithm presented in Fig. 4. 


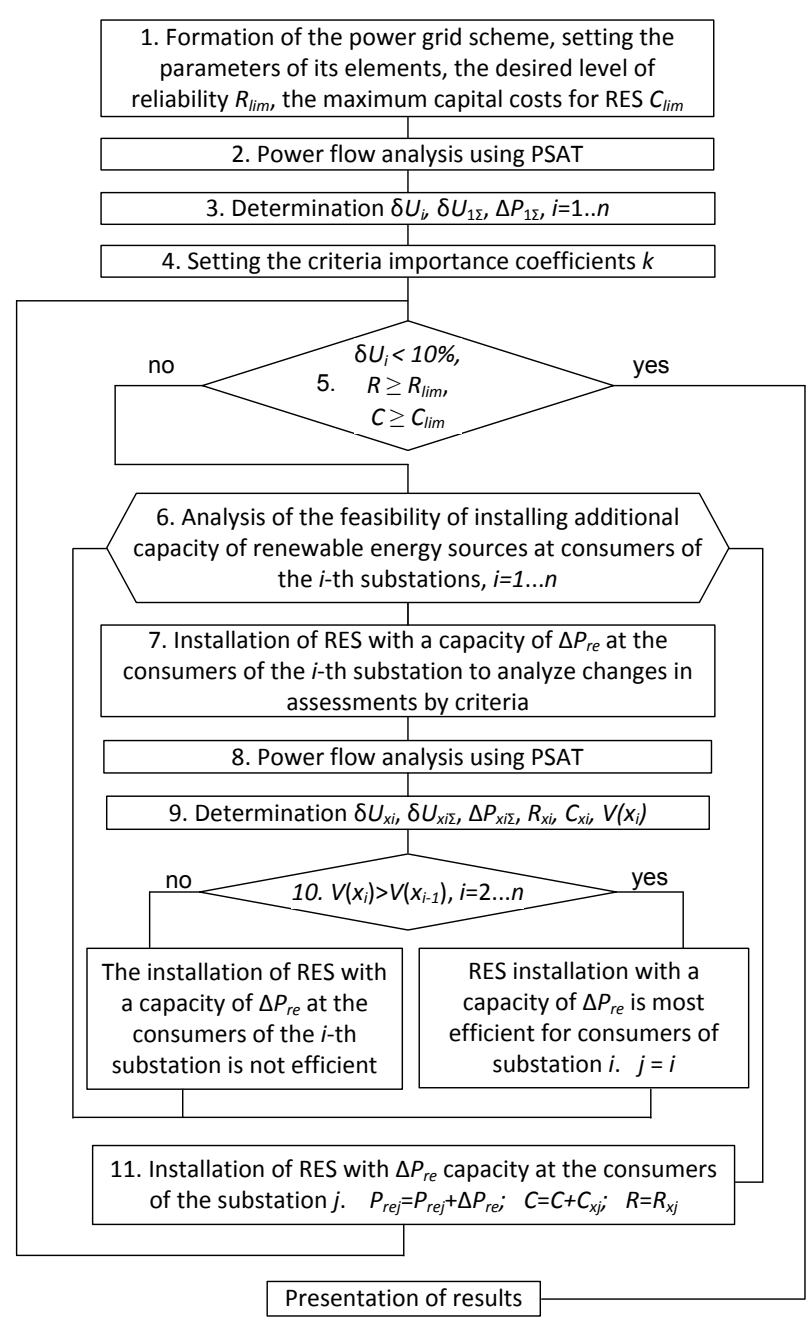

Fig. 4. Multi-criteria optimization algorithm.

At the first stage of the algorithm the desired level of reliability $R_{\text {lim }}$ is set, which determines what proportion of the load of the important consumers it is reasonable to reserve by RES. The limit of capital costs $C_{\text {lim }}$ is also set.

Further, using PSAT, the power flow analysis for the initial scheme is carried out, $\delta U_{i}, \delta U_{1 \Sigma}, \Delta P_{1 \Sigma}$ are determined by formulas (1)-(2).

Depending on the results of the previous stages, the DM determines the criteria importance coefficients $k_{1}$, $k_{2}, k_{3}, k_{4}$.

The optimization process is performed in blocks 511. At the fifth stage the conditions are checked, the set and parameters of which are set by DM. For example, if the voltage deviation at the consumers is less than $10 \%$, the desired level of reliability is reached and the costs have reached the limit value, optimization can be completed. If the conditions at stage 5 are not met, then a sequential check of the feasibility of adding power $\Delta P_{r e}$ to each of the considered substations supplying consumers is carried out. For this, the power flow analysis is carried out using PSAT and the objective function is calculated using expressions (1)-(5).

The decision to increase the RES installed capacity by $\Delta P_{r e}$ is made for the substation with the largest increase in the objective function relative to the initial value. After that, the conditions in block 5 are checked, the end or continuation of optimization is carried out.

The algorithm shown in Fig. 4 was implemented in MATLAB as a program. The working screen of the program (Fig. 5) contains a table, which reflects the results of the power flow analysis, performed in the PSAT at stages 2 or 8 (Fig. 4). On the left side of the screen, curves of the voltage on the load buses and voltage deviation are shown for the original power grid (in red) and for the power grid with RES (in green). On the right side of the screen, there are a curves showing the change in the objective function (in green) and individual indicators $\left(\delta U_{x \Sigma} / \delta U_{1 \Sigma}-\right.$ in red, $\Delta P_{x \Sigma} / \Delta P_{1 \Sigma}-$ in cyan, $R_{x}-$ in blue, $C_{x}$ - in black) at each iteration in the optimization process

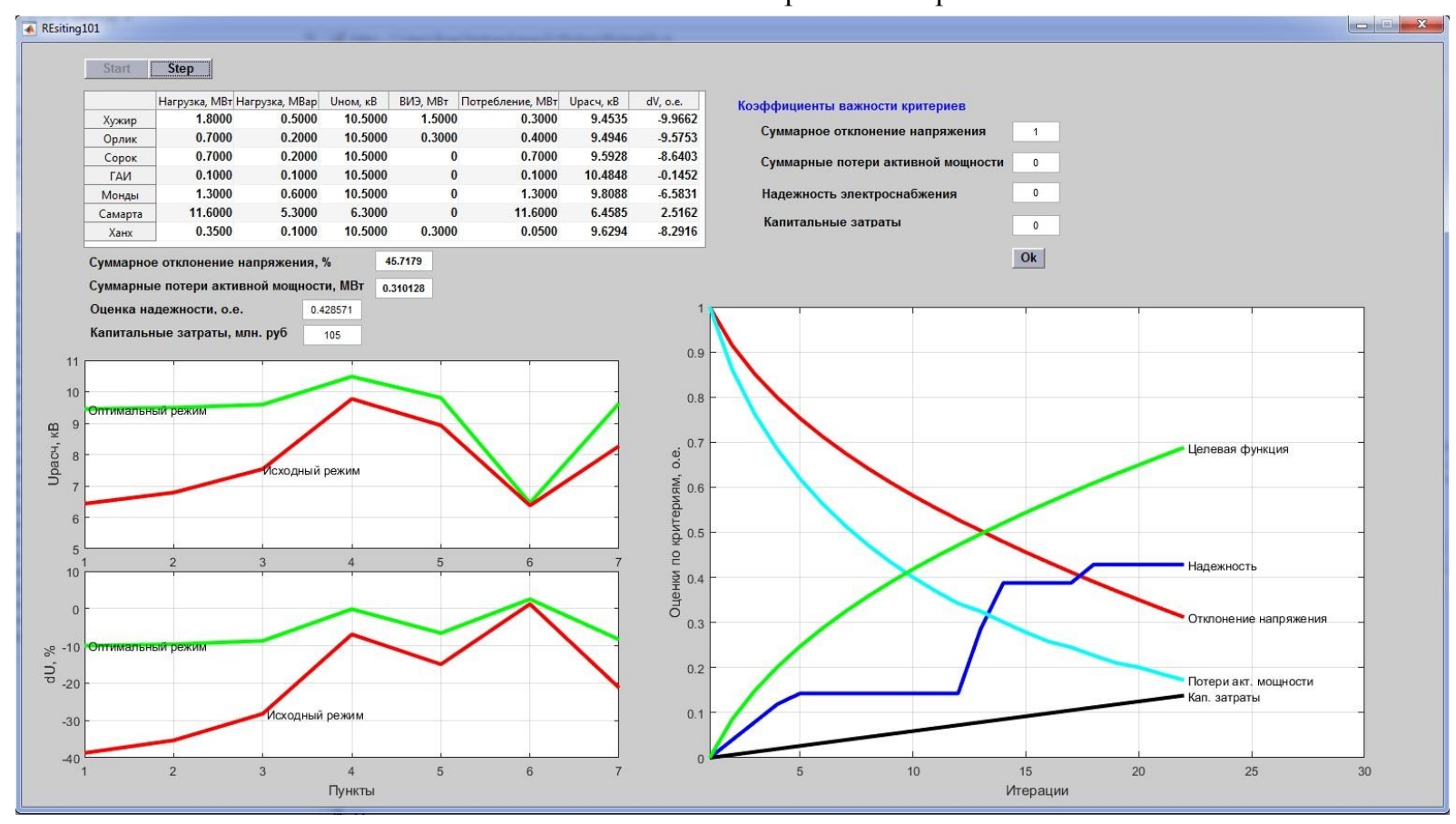

Fig. 5. Program interface for multicriteria optimization of RES locations and capacity. Results of one-criterion optimization. 
Presented in Fig. 5, Table 3 results correspond to the optimization performed according to one criterion $k_{1}$ total voltage deviation $\left(k_{1}=1 ; k_{2}=0 ; k_{3}=0 ; k_{4}=0\right)$ (Table 3). The optimization step $\Delta P_{r e}$ was equal to $0.1 \mathrm{MW}$.

Table 3. Results of assessing the voltage on the load buses.

\begin{tabular}{|l|c|c|c|}
\hline Locality & $\begin{array}{c}\text { RES } \\
\text { capacity, } \\
\text { MW }\end{array}$ & $\begin{array}{c}\text { Calculated } \\
\text { voltage, } \mathrm{kV}\end{array}$ & $\begin{array}{c}\text { Voltage } \\
\text { deviation, \% }\end{array}$ \\
\hline Khuzhir & 1.5 & 9.45 & -9.97 \\
\hline Orlik & 0.3 & 9.49 & -9.58 \\
\hline Sorok & 0 & 9.59 & -8.64 \\
\hline PTS & 0 & 10.48 & -0.15 \\
\hline Mondy & 0 & 9.81 & -6.58 \\
\hline Samarta & 0 & 6.46 & 2.52 \\
\hline Khankh & 0.3 & 9.63 & -8.29 \\
\hline
\end{tabular}

Table 3 shows that to reduce the voltage deviation at load buses to the permissible $10 \%$ by installing the SPP, it is advisable to place the photovoltaic modules in Khuzhir, Orlik, Khanh. The installed capacity of the SPP should make in the sum about 2,1 MW taking into account solar energy potential and climatic conditions of the regions. The total voltage deviation from the nominal value at the substations will make $45.72 \%$. Total active power losses $\Delta P_{\Sigma}=1.87 \%$. However, such variant of installation of SPP does not provide high assessment of power supply reliability. According to formula (3) at $L_{i}=0.2$, reliability assessment $R=0.43$ (with the maximum possible value equal to 1 ), since only three substations have RES redundancy. Capital costs for this option, according to (4), at $w=50$ thousand rubles / $\mathrm{kW}$ will be $C$ $=105$ million rubles.

Fig. 6 and Table 4 show the results of optimization carried out taking into account all criteria $\left(k_{1}=0.6\right.$; $\left.k_{2}=0.1 ; k_{3}=0.2 ; k_{4}=0.1\right)$.
Table 4. Results of assessing the voltage on the load buses.

\begin{tabular}{|l|c|c|c|}
\hline Locality & $\begin{array}{c}\text { RES } \\
\text { capacity, } \\
\text { MW }\end{array}$ & $\begin{array}{c}\text { Calculated } \\
\text { voltage, } \mathrm{kV}\end{array}$ & $\begin{array}{c}\text { Voltage } \\
\text { deviation, \% }\end{array}$ \\
\hline Khuzhir & 1.4 & 9.45 & -10 \\
\hline Orlik & 0.2 & 9.5 & -9.56 \\
\hline Sorok & 0.2 & 9.67 & -7.87 \\
\hline PTS & 0.1 & 10.53 & 0.26 \\
\hline Mondy & 0.3 & 9.9 & -5.74 \\
\hline Samarta & 0 & 6.46 & 2.57 \\
\hline Khankh & 0.2 & 9.59 & -8.68 \\
\hline
\end{tabular}

As a result of multi-criteria optimization, the assessment of the reliability of power supply increased to $R=0.86$, since the consumers of 6 substations have a reserve of RES with a load coverage share of more than $20 \%$. The total active power losses decreased to $\Delta P_{\Sigma}=1.75 \%$. However, in order to achieve permissible voltage deviations, it will be necessary to install SPP with a total capacity of $2.4 \mathrm{MW}$, the costs will be $C=120$ million rubles.

The performed review and obtained results allow to draw the following conclusions.

1. For sustainable socio-economic development of the "Baikal-Khövsgöl" Cross-Border Recreation Area, it is necessary to ensure environmentally efficient and reliable power supply to existing and prospective consumers in accordance with the requirements for the quality of electricity. The expected commissioning of the Konevinsky gold deposit will lead to unacceptable voltage deviations on the load buses of the Mondy, Khankh, Sorok, Orlik, Khuzhir substations, as well as high active power losses in the power distribution grid.

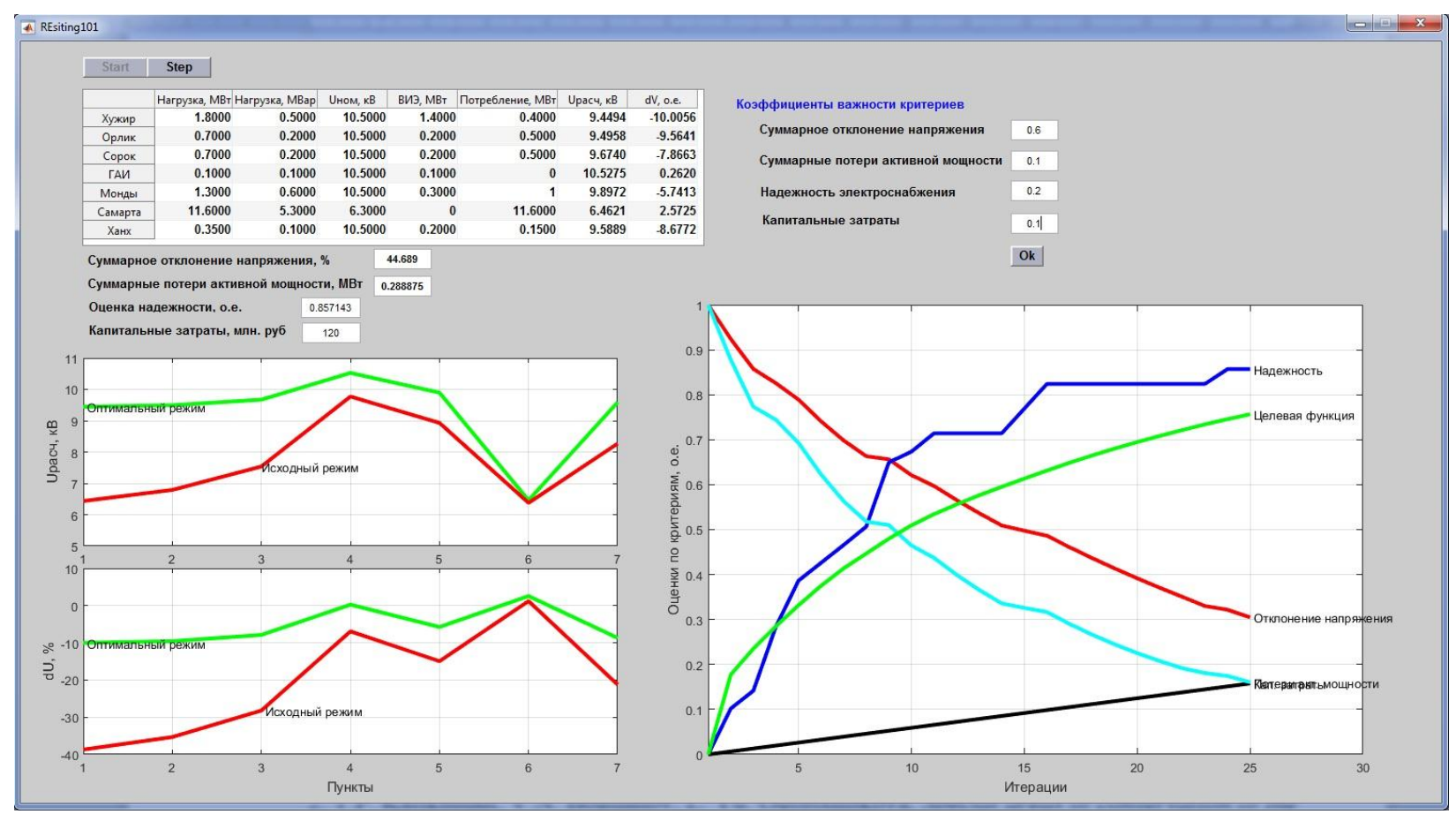

Fig. 6. Results of multi-criteria optimization of locations and capacity of SPP 
2. The area under consideration has a high level of solar energy potential. Installation of SPP in settlements will improve the reliability of power supply, ensure an acceptable voltage on the load buses, and reduce the loss of active power.

3. An algorithm and a program for multi-criteria optimization of RES locations and capacity are proposed. The program allows to get solutions that meet the preferences of the DM, expressed through the coefficients of importance.

4. Using the program, the variants of locations and installed capacity of SPP were obtained, which provide permissible voltage deviations at consumers, low total active power losses, high reliability of power supply.

This research was supported by a grant from the Foundation for Basic Research (project No. 18-510-94006).

\section{References}

1. O.V. Evstropieva Cross-border tourism in neighboring regions of Russia and Mongolia. Irkutsk: Publishing House of the V.B. Sochava Institute of Geography, Siberian Branch of the Russian Academy of Sciences. 143 p. (2009). (in Russian).

2. D. Enkhtaivan, O.V. Evstropieva, Cross-border tourism in Mongolia. Sovremennye problemy servisa i turizma. 9(4), P. 37-43. (2015) (in Russian)

3. G.Ya. Vagin. Comments on GOST R 54149-2010, the new standard for electric power quality, and its accompanying standards. Promyshlennaja energetika. 2013. No. 01, pp.39-43. (in Russian

4. I. Yu. Ivanova, V.A. Shakirov, N.A. Khalgaeva. Effects of the Adoption of Renewable Energy Sources within the "Baikal-Khövsgöl" Cross-Border Recreation Area. Energy Systems Research, 2(3). pp.11- 20. (2019).

5. F. Calderón-Vargas, D. Asmat-Campos, A. Carretero-Gómez. Sustainable Tourism and Renewable Energy: Binomial for Local Development in Cocachimba, Amazonas, Peru," Sustainability, Vol. 11(18), p. 4891 (2019).

6. S.T. Katircioglu. International tourism, energy consumption, and environmental pollution: The case of Turkey. Renew. Sustain. Energy Rev. 36, pp. 180-187 (2014).

7. M. Beer, R. Rybár, M. Kal'avský. Renewable energy sources as an attractive element of industrial tourism. Current Issues in Tourism, 21(18), pp. 2139-2151 (2018).

8. N. Khaboot, R. Chatthaworn, A. Siritaratiwat, C. Surawanitkun, P. Khunkitti. Increasing PV penetration level in low voltage distribution system using optimal installation and operation of battery energy storage. Cogent Engineering, 6(1), 1641911 (2019).

9. R.R. Nasyrov, R.I. Aljendy, T. Kherbek. Determining the power of renewable energy sources to cover the shortage of active. Electric power. Transmission and distribution. No. 5 (56). pp. 72-77. (2019). (in Russian).

10. M.M. Aman, G.B. Jasmon, K.H. Solangi, A.H.A Bakar, H. Mokhlis. Optimum simultaneous DG and capacitor placement on the basis of minimization of power losses. International Journal of Computer and Electrical Engineering, 5, no. 5, pp. 516-522. (2013).

11. H.R. Esmaeilian, O. Darijany, M. Mohammadian. Optimal placement and sizing of DG units and capacitors simultaneously in radial distribution networks based on the voltage stability security margin. Turkish Journal of Electrical Engineering \& Computer Science, pp. 1-14. (2014).

12. S. Naik, D.K. Gopiya, D.K. Khatod, M.P. Sharma. Optimal allocation of combined DG and capacitor for real power loss minimization in distribution networks. International Journal of Electrical Power \& Energy Systems, 53, pp. 967-973. (2013).

13. K. Muthukumar, S. Jayalalitha. Optimal placement and sizing of distributed generators and shunt capacitors for power loss minimization in radial distribution networks using hybrid heuristic search optimization technique. International Journal of Electrical Power \& Energy Systems, 78, pp. 299319. (2016).

14. A. Khodabakhshian, H. Mohammad. Simultaneous placement and sizing of DGs and shunt capacitors in distribution systems by using IMDE algorithm. International Journal of Electrical Power \& Energy Systems, 82, pp. 599-607. (2016).

15. A. Edelev, D. Karamov, I. Sidorov, D.V. Binh, N.H. Nam, N.H. Anh, P.V. Duy, P.T. Hanh. Modelling energy systems of Vietnam with integration of renewable power sources. CEUR Workshop Proceedings. Vol. 2430. pp. 42-50. (2019).

16. M. Rahmani. Simultaneous placement of DG and capacitor in distribution network. Electric Power Systems Research, 131, pp. 1-10. (2016).

17. S.A. Mehran, A. Mojtaba, T.H. Yaser. Optimal allocation of distributed generations and shunt capacitors using salp swarm algorithm. 26-th Iranian Conference on Electrical Engineering (ICEE 2018), pp. 1166-1172. (2018).

18. L. Vanfretti, F. Milano. Application of the PSAT, an Open Source Software, for Educational and Research Purposes. 2007 IEEE Power Engineering Society General Meeting, Tampa, FL, 2007, pp. 1-7.

19. R.K. Rietz, S. Suryanarayanan. A review of the application of analytic hierarchy process to the planning and operation of electric power microgrids. 2008 40th North American Power Symposium, Calgary, AB, pp. 1-6, (2008).

20. J.S. Dyer. MAUT. In: Figueira, J.R., et al. (eds.) Multiple Criteria Decision Analysis: State of the Art Surveys, pp. 265-295. Springer, New York (2005). 